\title{
Methanol Extract of Flacourtia indica Aerial Parts Induces Apoptosis via Generation of ROS and Activation of Caspases in Human Colon Cancer HCT116 Cells
}

\author{
Ki-Woong Park ${ }^{1 \&}$, Juthika Kundu ${ }^{1 \&}$, In Gyeong Chae ${ }^{1}$, Sitesh Chandra Bachar ${ }^{2}$, \\ Jung-Woo Bae ${ }^{1 *}$, Kyung-Soo Chun ${ }^{1 *}$
}

\begin{abstract}
Different plant parts of Flacourtia indica have long been used in Ayurvedic medicine. Previous studies have demonstrated that the methanolic extract of $F$. indica possess anti-inflammatory properties. The present study was aimed at investigating the anticancer effects of methanol extract of Flacourtia indica (FIM) aerial parts in human colon cancer (HCT116) cells. Treatment of cells with FIM at a concentration of $500 \mu \mathrm{g} / \mathrm{ml}$ for 24 hours significantly reduced cell viability and induced apoptosis, which was associated with the increased cytoplasmic expression of cytochrome c, activation of caspase-3, and the cleavage of poly-(ADP-ribose) polymerase. Incubation with FIM also inhibited the levels of Bcl-2, Bcl-xl and survivin, which are the markers of cell proliferation, whereas the expression of Bax remained unchanged. Treatment with FIM led to the generation of reactive oxygen species (ROS) in a concentration-dependent manner. Pharmacological inhibition of ROS generation by pretreatment of cells with $\mathrm{N}$-acetyl cysteine abrogated FIM-induced apoptosis in HCT116 cells. Thus, these results demonstrate that FIM has anti-proliferative and pro-apoptotic effects in HCT116 cells and the effects are, at least in part, due to the ROS dependent activation of caspases.
\end{abstract}

Keywords: Flacourtia indica - colon cancer cells - caspase - reactive oxygen species - apoptosis

Asian Pac J Cancer Prev, 15 (17), 7291-7296

\section{Introduction}

The World Health Organization (WHO) reports that about $80 \%$ of the population in developing countries relies on the traditional system of medication for primary health care. Traditional medicines in the form of standardized herbal preparations are also gaining popularity in many developed countries (Pal and Shukla, 2003). A broad spectrum of secondary metabolites present in herbs is effective in the treatment and/or prevention of various chronic diseases, including cancer (Chun et al., 2013; Kundu and Surh, 2005; Shukla and Pal, 2004). Colorectal cancer ranks as the fourth most common cancer in men and the third most common in women worldwide, accounting for about $8 \%$ of all cancer-related deaths (Kamangar et al., 2006; Moghimi-Dehkordi and Safaee, 2012). A wide variety of plants extracts as well as purified phytochemicals have been shown to prevent colon carcinogenesis (Chun et al., 2013; Kim et al., 2008; Vayghan et al., 2014).

Flacourtia indica (Burm. F) Merr. (familyFlacourtiaceae; Bengali Name - Baichi, 'Madagascar plum' in English) is a medium-sized, bushy, thorny tree available in the rural areas of Bangladesh and India
(Kaou et al., 2010). Different parts of this plant have long been used in Ayurvedic medicine. Previous studies have demonstrated the antibacterial (Eramma and Devaraja, 2013) antimalarial (Kaou et al., 2010), hepatoprotective (Nazneen et al., 2009) and anti-inflammatory (Kundu et al., 2013) activities of methanol extract of $F$. indica (FIM). Moreover, phytochemical analysis of the plant revealed the presence of several bioactive constituents, such as coumarins (Nazneen et al., 2002) and phenolic glycosides (Kaou et al., 2010). Since plant polyphenols possess anticancer properties, the present study was aimed at investigating the possible anticancer activity of FIM in human colon cancer HCT116 cells and to elucidate its underlying mechanisms. One of the hallmarks of cancer is the evasion of tumor cells from apoptosis (Hanahan and Weinberg, 2011). Numerous plant products have been reported to induce apoptosis in various cancer cells, thereby eliciting anticancer properties (Kundu and Surh, 2005). Here, we report that FIM induces apoptosis in human colon cancer (HCT116) cells through the generation of reactive oxygen species (ROS), activation of caspases and the inhibition of proliferative markers. 


\section{Materials and Methods}

\section{Preparation of plant extract}

The aerial parts of Flacourtia indica were collected from Sripur of Gazipur district of Bangladesh and a voucher specimen has been deposited in the Herbarium of Department of Botany, University of Dhaka, Bangladesh. The plant was sun-dried for fifteen days and then pulverized. The coarse powder $(700 \mathrm{~g})$ was extracted with methanol by cold extraction process. All the extracts obtained were filtered off and evaporated to dryness in vacuuo at low temperature and reduced pressure by rotary evaporator. The bioactivity of only the methanol extract was investigated in the present study. FIM was dissolved in dimethylsulfoxide (DMSO) immediately before treatment of cells.

\section{Materials}

$\mathrm{N}$-acetyl cysteine (NAC) was purchased from Sigma-Aldrich (St Louis, MO, USA). Antibodies against cleaved caspase-3, cytochorome c, cleaved PARP, Bcl-2, Bcl-xl, Bax, survivin were procured from Cell Signaling Technology Inc. (Beverly, MA, USA). Horse-raddish peroxidase-conjugated secondary antibodies were purchased from SantaCruz Biotechnology (SantaCruz, CA, USA). $\beta$-Actin antibody was obtained from Sigma Chemical Co. (St Louis, MO, USA). The 2'-7'-dichlorofluorescin diacetate (DCF-DA) was procured from Invitrogen (Carlsbad, CA, USA). Hank's balanced salt solution (HBSS) was purchased from Meditech (Herndon, VA, USA). All other chemicals were of analytical or highest purity grade available.

\section{Cell culture and treatment}

HCT116 cells were obtained from American Type Culture Collections and maintained in RPMI 1640 supplemented with $10 \%$ fetal bovine serum and antibiotics (100 $\mathrm{U} / \mathrm{ml}$ penicillin $\mathrm{G}$ and $100 \mu \mathrm{g} / \mathrm{ml}$ streptomycin) at $37^{\circ} \mathrm{C}$ in a humidified incubator containing $5 \% \mathrm{CO}_{2}$ and $95 \%$ air. In all the experiments, cells were seeded at $2 \times 10^{5}$ cells $/ \mathrm{ml}$ and incubated with FIM at $50-60 \%$ confluence. All chemicals were dissolved in DMSO keeping its final concentration at less than $1 \%$.

\section{Cell proliferation assay}

The anti-proliferative effect of FIM against HCT116 cells was measured by using a solution of tetrazolium compound 3- (4, 5-dimethylthiazol-2yl)- 5- (3-carboxymethoxyphenyl) -2 -(4-sulfophenyl) -2H-tetrazolium, inner salt (MTS) (Promega, WI, USA). Briefly, cells $\left(2 \times 10^{3}\right)$ were incubated in triplicate in a 96-well plate in presence or absence of FIM in a final volume of $0.1 \mathrm{ml}$ for different time intervals at $37^{\circ} \mathrm{C}$. Thereafter, $20 \mu \mathrm{l}$ of MTS solution was added to each well and incubated for $60 \mathrm{~min}$. The number of viable cells was measured in a 96-well plate at an optical density of $492 \mathrm{~nm}$ on a microplate reader (Tecan Trading AG, Switzerland). Cell viability was described as the relative percentage of control.

\section{Annexin V staining}

Annexin V staining was performed using FITCAnnexin V staining kit (BD-Biosciences, San Jose, CA, USA) following the manufacturer's instructions. Briefly, cells incubated with or without FIM were washed with PBS and resuspended in binding buffer containing Annexin $\mathrm{V}$ and propidium iodide. Flourescence intensity was measured using flow cytometry (BD Biosciences, San Jose, CA, USA).

\section{Western blot analysis}

Cells were harvested and lysed with RIPA buffer, and collected protein samples were quantified by using bichinconinic acid protein assay kit (Pierce Biotechnology, Rockford, IL, USA). The protein samples were separated by sodium dodecyl sulfate-polyacrylamide gel electrophoresis and immunoblot analysis was done according to the protocol described earlier (Kundu et al., 2012). Immunoblot membranes were incubated with Super-signal pico-chemiluminescent substrate or dura-luminol substrate (Thermo Scientific, MA, USA) according to manufacturer's instruction and visualized with imagequant ${ }^{\mathrm{TM}}$ LAS 4000 (Fujifilm Life Science, Japan).

\section{Measurement of ROS accumulation}

Cells were treated with FIM in the presence or absence of NAC for $24 \mathrm{~h}$ and then loaded with $25 \mu \mathrm{M}$ of DCFDA. After incubation for $30 \mathrm{~min}$ at $37^{\circ} \mathrm{C}$ in a $5 \% \mathrm{CO}_{2}$ incubator, cells were washed twice with HBSS solution, suspended in the complete media and were examined under a fluorescence microscope to detect the intracellular accumulation of ROS. Fourescence of oxidized DCF was also measured at an excitation wave length of $480 \mathrm{~nm}$ and emission wavelength of $525 \mathrm{~nm}$ using a flow cytometer.

\section{Statistical analysis}

When necessary, data were expressed as mean \pm SD of at least three independent experiments, and statistical analysis for single comparison was performed using the Student's t-test. $* \mathrm{p}<0.01$ and $* * \mathrm{p}<0.001$ as compared to control.

\section{Results}

Treatment with FIM inhibits cell growth and induces apoptosis in HCT116 cells

We initially examined the effect of FIM on the viability of HCT116 cells by MTS assay. Incubation of cells with FIM $(100,200$ or $500 \mu \mathrm{g} / \mathrm{ml})$ reduced the cell viability in a time- and concentration-dependent manner (Figure 1A). Annexin V staining of cells treated with indicated concentrations of FIM showed a concentration- and timedependent induction of apoptosis (Figure 1B).

\section{Effects of FIM on the expression of apoptotic markers}

To elucidate the mechanisms underlying growth inhibitory effects of FIM, the expression of several major apoptosis regulating proteins were measured by the Western blot analysis. Caspases are important mediators 
of apoptosis and contribute to the overall apoptotic morphology by cleavage of various cellular substrates. PARP, a known caspase substrate, is a $116 \mathrm{kDa}$ nuclear protein that is specifically cleaved by active caspase-3 into an $85 \mathrm{kDa}$ (Janicke et al., 1998). Incubation of the HCT116 cells with FIM for $24 \mathrm{~h}$ increased the expression level of caspase-3, cytochrome $c$ and induced the cleavage of PARP in HCT116 cells (Figure 2A). As shown in Figure 2B, FIM treatment led to a concomitant decrease in the level of Bcl-2 and Bcl-xl in a concentration-dependent manner, whereas the expression of Bax remained unchanged. In addition, treatment of cells with FIM for $24 \mathrm{~h}$ decreased the expression of survivin, a cell survival protein known to inhibit apoptosis (Altieri, 2003).
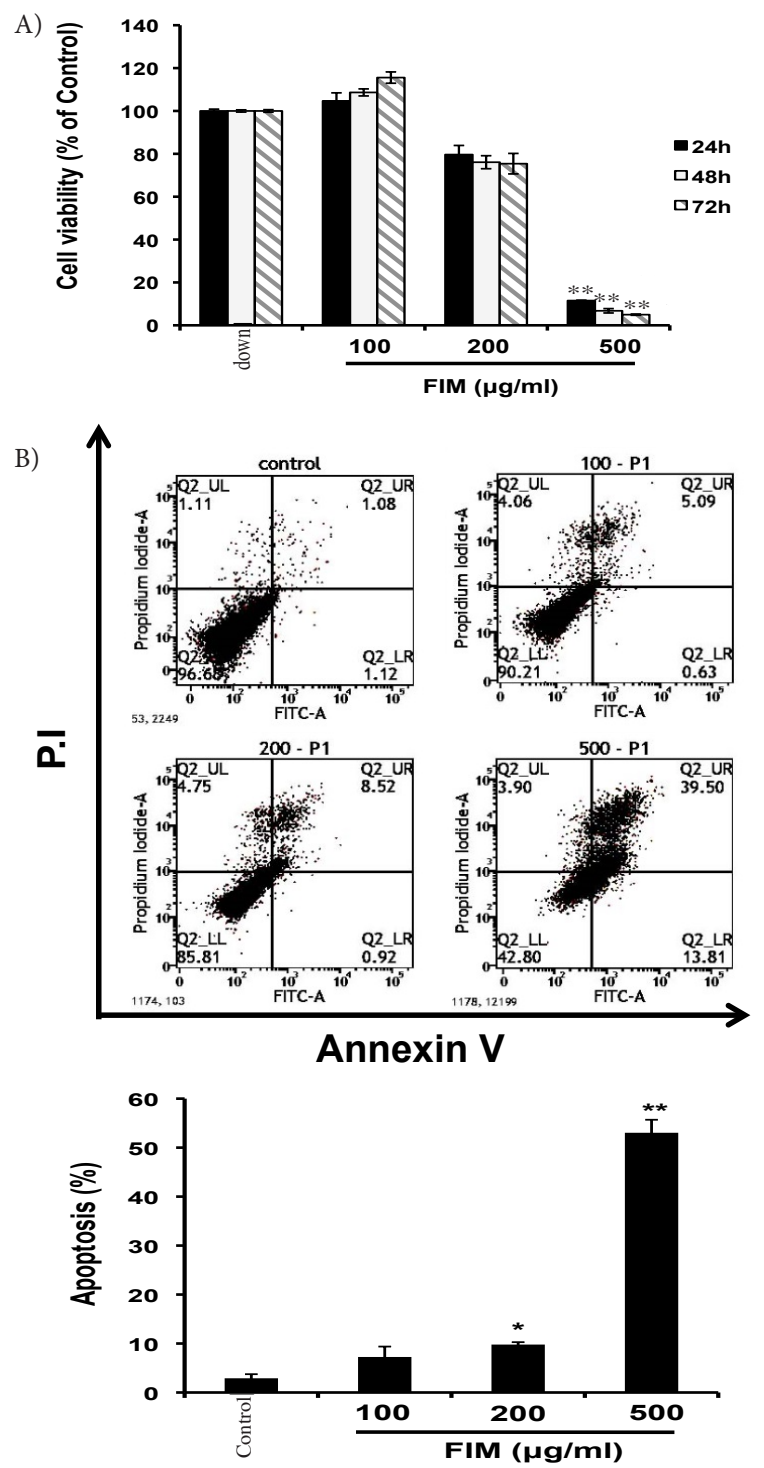

Figure 1. FIM Inhibits Proliferation and Induces Apoptosis in HCT116 Cells. (A) Cells were treated with indicated concentrations of FIM for 24, 48 or $72 \mathrm{~h}$. Cell viability was determined by the MTS assay; Values are expressed as means \pm SD; $* \mathrm{p}<0.01 * * \mathrm{p}<0.001$, compared to control. (B) The apoptotic index $(\%)$ was determined by flow cytometry upon treatment of cells with FIM $(100,200$ or $500 \mu \mathrm{g} / \mathrm{ml})$ for $24 \mathrm{~h}$ and staining with Annexin V and propidium iodide (P.I). Lower panel shows statistical analysis of apoptosis. Data are representative of three independent experiments

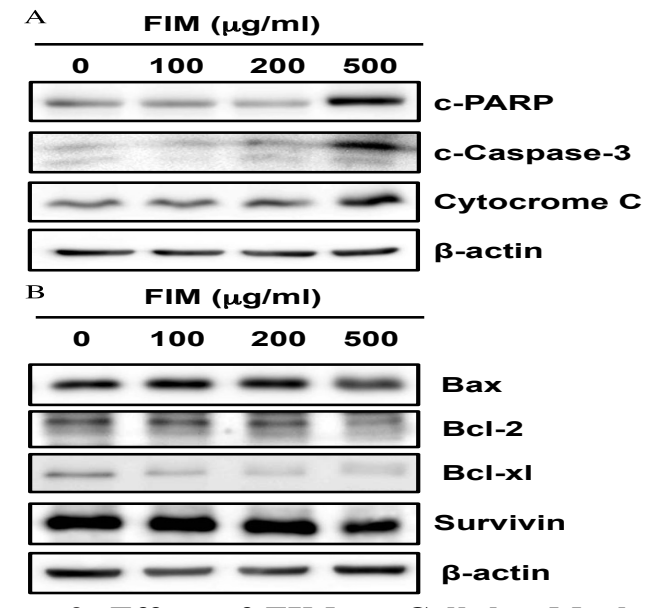

Figure 2. Effect of FIM on Cellular Markers of Apoptosis in HCT116 Cells. Cells were incubated with FIM $(100,200$ and $500 \mu \mathrm{g} / \mathrm{ml})$ for $24 \mathrm{~h}$. The levels of (A) cleaved PARP, cleaved caspase-3 and cytochrome $\mathrm{c}$ and (B) Bax, Bcl-2, $\mathrm{Bcl}-\mathrm{xl}$ and survivin were determined by Western blot analysis. Immunoblots are representative of three different experiments showing a similar pattern
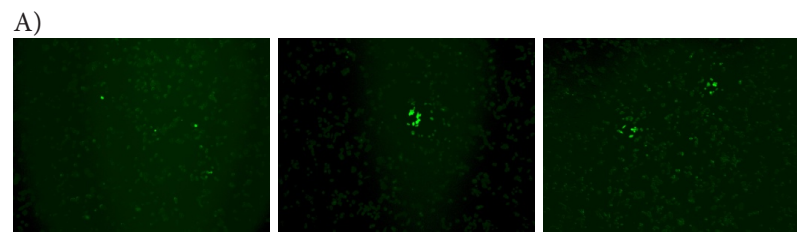

Control FIM $100 \mu \mathrm{g} / \mathrm{ml}$ FIM $200 \mu \mathrm{g} / \mathrm{ml}$

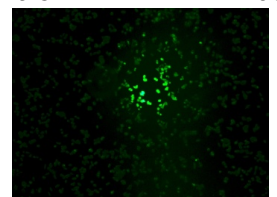

FIM $500 \mu \mathrm{g} / \mathrm{ml}$

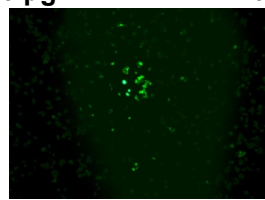

B)
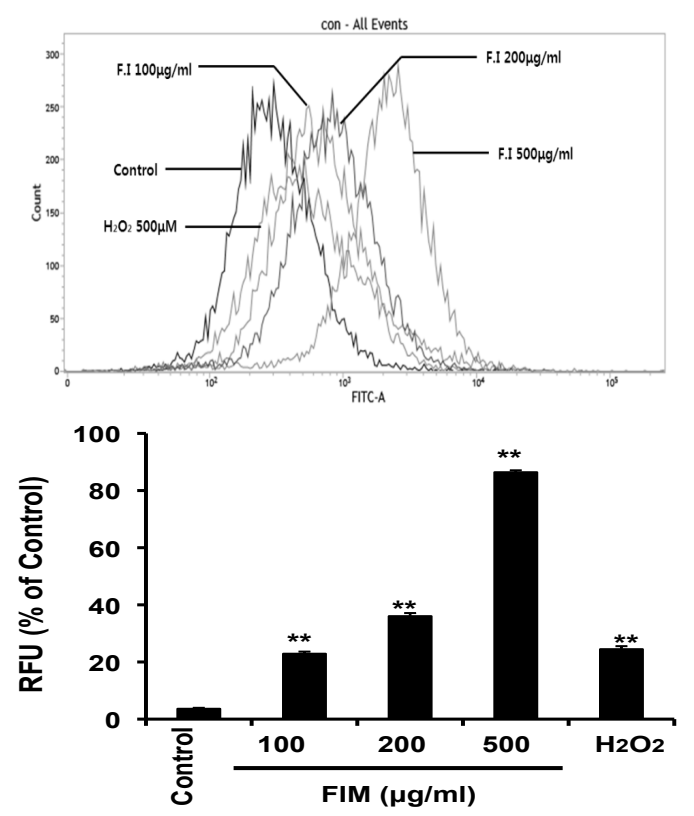

Figure 3. FIM Induces ROS Generation in HCT116 Cells. (A, B) Cells were treated with FIM (100, 200 or $500 \mu \mathrm{g} /$ $\mathrm{ml}$ ) for $2 \mathrm{~h}$ and then examined for the intracellular accumulation of ROS (A) under the fluorescence microscope using DCF-DA fluorescence staining method (x200) or (B) measured by flow cytometry. The experiment was done in triplicate and the data presented as mean $\pm \mathrm{SD}$. Lower panel shows statistical analysis of ROS generation. $* * \mathrm{p}<0.001$ (as compared to control) 
A)

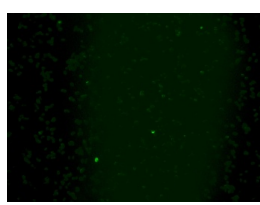

Control

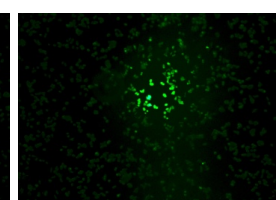

FIM



NAC + FIM

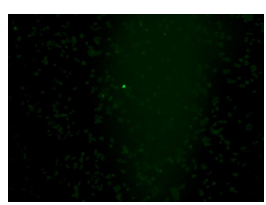

NAC
B)

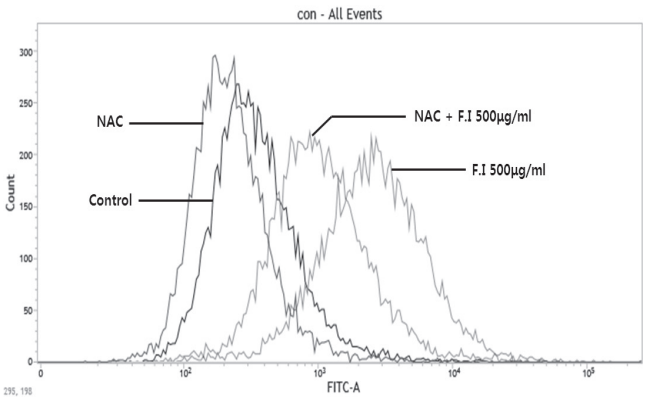

C)

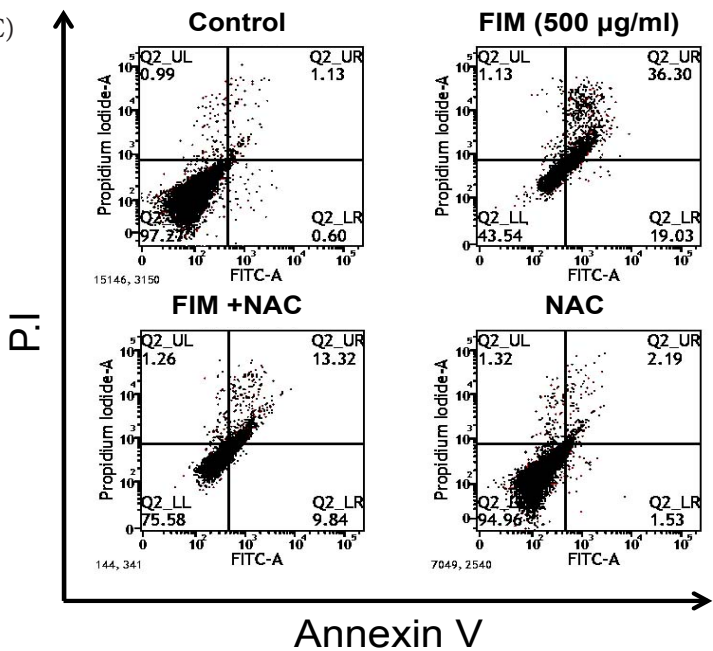

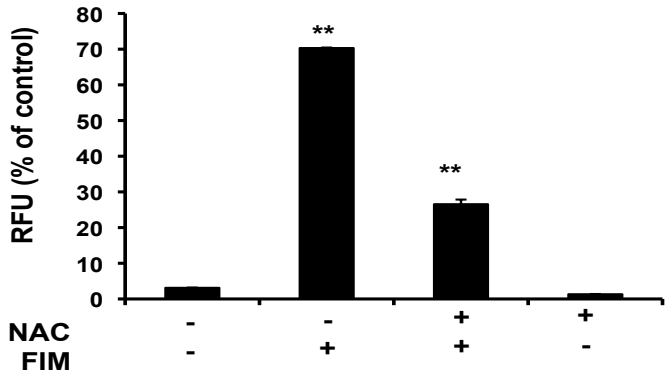

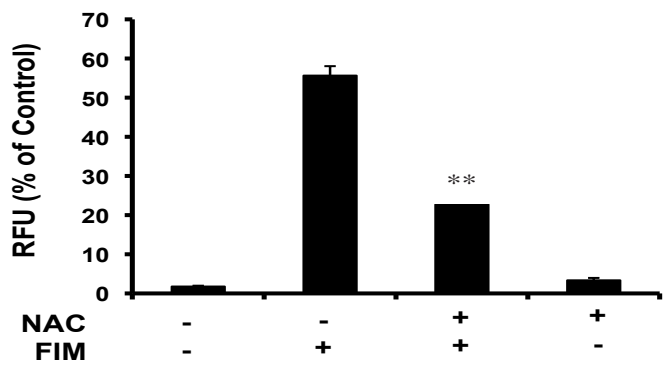

Figure 4. Involvement of ROS in FIM-induced Apoptosis. Cells were treated with NAC ( $5 \mathrm{mM}) 1 \mathrm{~h}$ before treatment with FIM $(500 \mu \mathrm{g} / \mathrm{ml})$ for $2 \mathrm{~h}$. ROS levels were measured either by (A) fluorescence microscopy or (B) by flow cytometry. The experiment was done in triplicate and lower panel showed the data presented as mean $\pm \mathrm{SD}$. $* * \mathrm{p}<0.001$ (control versus FIM; FIM versus NAC plus FIM). (C) The apoptotic index (\%) was determined by flow cytometry upon treatment of cells with NAC (5 mM) $1 \mathrm{~h}$ before treatment with FIM $(500 \mu \mathrm{g} / \mathrm{ml})$ for $2 \mathrm{~h}$ and staining with Annexin $\mathrm{V}$ and propidium iodide (P.I). Lower panel shows statistical analysis of apoptosis. Data are representative of three independent experiments. ${ }^{* *} \mathrm{p}<0.001$ (control versus FIM; FIM versus NAC plus FIM)

Generation of ROS is important in FIM-induced growth inhibition and apoptosis in HCT116 cells

Accumulation of intracellular ROS induces cell death. We examined the effect FIM on ROS generation. Treatment of cells with FIM generated ROS in concentration dependent manner as revealed by immunofluorescence analysis upon DCF-DA staining (Figure 3A) as well as by FACS analysis (Figure 3B). As shown in Figure 4A and 4B, FIM-induced ROS generation was abrogated by pretreatment of cells with NAC (Figure 4A and 4B). Moreover, cells treated with NAC abrogated FIM-induced apoptosis of HCT116 cells as revealed by Annexin V staining method (Figure 4C).

\section{Discussion}

Extractives of the medicinal plant Flacourtia indica have been reported to exert a broad range of pharmacological activities, such as antimalarial, hepatoprotective, analgesic, diuretic and anti-inflammatory activities (Eramma and Devaraja, 2013; Kaou et al., 2010; Kundu et al., 2013; Nazneen et al., 2009). Phytochemical investigation of the plant has revealed the presence of a wide variety of bioactive phytochemicals including coumarins (Nazneen et al., 2002) and phenolic glycosides (Kaou et al., 2010), of which a coumarin compound scoparone has been reported to possess anti-inflammatory (Jang et al., 2005) and anticancer activities (Kim et al., 2013). Because of the causal link between inflammation and cancer, numerous plant extractives as well as purified plant constituents retaining anti-inflammatory properties have been shown to possess anticancer activity (Abdull Razis and Noor, 2013; Sehitoglu et al., 2014). We, therefore, examined the anticancer potential of methanolic extracts of the aerial parts of $F$. indica in the present study.

Our study revealed that FIM elicited significant cytotoxic effect in HCT116 colon cancer cells in a timeand concentration-dependent manner. In an attempt to elucidate the underlying mechanism of FIM-induced colon cancer cell death, we examined the effect of FIM on cellular apoptotic markers. The findings that the incubation with FIM induced the cleavage of caspase-3 and PARP confirm the ability of this plant extract to induce cancer cell death. Since the activation of caspase-3, which brings 
about catastrophic degradation of various intracellular proteins, depends on the destabilization of mitochoindrial membrane potential and release of cytochrome c (Earnshaw et al., 1999), our findings that FIM upregulates cytosolic protein expression of cytochrome $\mathrm{c}$ indicates that FIM induced apoptosis in a mitochondria-mediated mechanism.

Although the understanding of whether FIM can decrease mitochondrial membrane potential is still unclear, our study provides convincing evidence in support of a mitochondria-mediated cell death induced by this plant extract. It was previously shown that the reduced expression of $\mathrm{Bcl}-2$ leads to the dysfunction of mitochondria resulting in the release of intermembrane protein cytochrome $\mathrm{c}$ that functions in activation of caspase-9, which subsequently cleaves procaspase-7 and -3 (Borner, 2003). So the upregulated expression of cytochorome c by FIM may lead to the activation of caspase-9. Moreover, the increased mitochondrial membrane attachment of Bax, a proapoptotic protein, can promote cytochrome c release (Banjerdpongchai et al., 2011). We, therefore, examined the effect of FIM on the expression of several Bcl-2 family proteins and found that FIM markedly diminished the expression of antiapoptotic protein $\mathrm{Bcl}-2$ and $\mathrm{Bcl}-\mathrm{xl}$ without altering that of the proapoptotic protein Bax. Since Bcl-2 is overexpressed in colon cancer (Hasan et al., 2011) and the Bcl-2-mediated inhibition of apoptosis restores the tumorigenecity of spontaneously regressed colon tumors in vivo (Bonnotte et al., 1998), the inhibitory effect of FIM on Bcl-2 and Bcl-xl expression, thus, provides a mechanistic basis of its colon cancer preventive effects. FIM also attenuated the expression of survivin, another cell proliferation marker, which has been reported to inhibit Fas-mediated apoptosis in cancer cells (Asanuma et al., 2004). Thus, the downregulation of survivin expression by FIM suggests that FIM may induce apoptosis by activating Fas-mediated signaling, which merits further investigation.

One of the triggers of mitochondrial dysfunction is the accumulation of intracellular ROS. Many of the alcoholic extracts of medicinal plants are reported to induce ROSdependent apoptosis in cancer cells (Banjerdpongchai and Kongtawelert, 2011; Yeh et al., 2012). We examined whether FIM can induce ROS generation as a mechanism of its cytotoxic effects. Our finding that FIM induced ROS generation, which was abrogated by pretreatment with ROS scavenger NAC, suggests that the cytotoxic effect of FIM is dependent on its ability to generate ROS. This speculation has been confirmed by the finding that when cells were pre-incubated with NAC, the cytotoxic effect of FIM was reverted.

Despite the remarkable apoptotic effect of FIM, it still remains elusive which specific component(s) are responsible for this effect. However, scoparone, present in F. indica (Nazneen et al., 2002), elicited antitumor activity in DU145 prostate cancer cells via down regulation of Stat3 signaling pathway (Kim et al., 2013). Thus, the observed cytotoxic effect of FIM may be partly attributed to scoparone present in this plant. In conclusion, the present study demonstrates for the first time that FIM induced generation of ROS, activation of caspases and downregulation of Bcl-2, Bcl-xl and survivin, thereby inducing apoptosis in HCT116 cells.

\section{Acknowledgements}

This study was supported by the College of Pharmacyspecialized Research Fund (the Institute for New Drug Development) of Keimyung University in 2013.

\section{References}

Abdull Razis AF, Noor NM (2013). Cruciferous vegetables: dietary phytochemicals for cancer prevention. Asian Pac J Cancer Prev, 14, 1565-70.

Altieri DC (2003). Survivin in apoptosis control and cell cycle regulation in cancer. Prog Cell Cycle Res, 5, 447-52.

Asanuma K, Tsuji N, Endoh T, Yagihashi A, Watanabe N (2004). Survivin enhances Fas ligand expression via up-regulation of specificity protein 1-mediated gene transcription in colon cancer cells. J Immunol, 172, 3922-9.

Banjerdpongchai R, Kongtawelert P (2011). Ethanolic extract of fermented Thunb induces human leukemic HL-60 and Molt-4 cell apoptosis via oxidative stress and a mitochondrial pathway. Asian Pac J Cancer Prev, 12, 2871-4.

Banjerdpongchai R, Punyati P, Nakrob A, Pompimon W, Kongtawelert P (2011). 4'-Hydroxycinnamaldehyde from Alpinia galanga (Linn.) induces human leukemic cell apoptosis via mitochondrial and endoplasmic reticulum stress pathways. Asian Pac J Cancer Prev, 12, 593-8.

Bonnotte B, Favre N, Moutet M, et al (1998). Bcl-2-mediated inhibition of apoptosis prevents immunogenicity and restores tumorigenicity of spontaneously regressive tumors. J Immunol, 161, 1433-8.

Borner C (2003). The Bcl-2 protein family: sensors and checkpoints for life-or-death decisions. Mol Immunol, 39, 615-47.

Chun KS, Kim EH, Lee S, Hahm KB (2013). Chemoprevention of gastrointestinal cancer: the reality and the dream. Gut Liver, 7, 137-49.

Earnshaw WC, Martins LM, Kaufmann SH (1999). Mammalian caspases: structure, activation, substrates and functions during apoptosis. Annu Rev Biochem, 68, 383-424.

Eramma N, Devaraja G (2013). Antibacterial potential and phytochemical analysis of Flacourtia indica (Burm.f.) Merr. root extract against human pathogens. Indo Am J Pharm Res, 3, 3832-46.

Hanahan D, Weinberg RA (2011). Hallmarks of cancer: the next generation. Cell, 144, 646-74.

Hasan TN, Leena GB, Shafi G, Al-Hazzani AA, Alshatwi AA (2011). Anti-proliferative effects of organic extracts from root bark of Juglans Regia L. (RBJR) on MDA-MB-231 human breast cancer cells: role of Bcl-2/Bax, caspases and Tp53. Asian Pac J Cancer Prev, 12, 525-30.

Jang SI, Kim YJ, Lee WY, et al (2005). Scoparone from Artemisia capillaris inhibits the release of inflammatory mediators in RAW 264.7 cells upon stimulation cells by interferon-gamma Plus LPS. Arch Pharm Res, 28, 203-8.

Janicke RU, Sprengart ML, Wati MR, Porter AG (1998). Caspase-3 is required for DNA fragmentation and morphological changes associated with apoptosis. $J$ Biol Chem, 273, 9357-60.

Kamangar F, Dores GM,Anderson WF (2006). Patterns of cancer incidence, mortality, and prevalence across five continents: defining priorities to reduce cancer disparities in different geographic regions of the world. J Clin Oncol, 24, 2137-50.

Kaou AM, Mahiou-Leddet V, Canlet C, et al (2010). Antimalarial compounds from the aerial parts of Flacourtia indica 
(Flacourtiaceae). J Ethnopharmacol, 130, 272-4.

Kim HS, Kundu JK, Lee JS, et al (2008). Chemopreventive effects of the standardized extract (DA-9601) of Artemisia asiatica on azoxymethane-initiated and dextran sulfate sodium-promoted mouse colon carcinogenesis. Nutr Cancer, 60, 90-7.

Kim JK, Kim JY, Kim HJ, et al (2013). Scoparone exerts antitumor activity against DU145 prostate cancer cells via inhibition of STAT3 activity. PLoS One, 8, e80391.

Kundu J, Roy M, Bachar SC, Chun KS, Kundu JK (2013). Analgesic, anti-inflammatory, and diuretic activity of methanol extract of Flacourtia indica. Arch Basic Appl Med, 1, 39-44.

Kundu J, Wahab SM, Kundu JK, et al (2012). Tob1 induces apoptosis and inhibits proliferation, migration and invasion of gastric cancer cells by activating Smad4 and inhibiting betacatenin signaling. Int J Oncol, 41, 839-48.

Kundu JK, Surh YJ (2005). Breaking the relay in deregulated cellular signal transduction as a rationale for chemoprevention with anti-inflammatory phytochemicals. Mutat Res, 591, 123-46.

Moghimi-Dehkordi B, Safaee A (2012). An overview of colorectal cancer survival rates and prognosis in Asia. World J Gastrointest Oncol, 4, 71-5.

Nazneen N, Mazid MA, Kundu JK, et al (2009). Protective effects of Flacourtia indica aerial parts extract against paracetamol-induced hepatotoxicity in rats. J Taibah Univ Sci, 2, 1-6.

Nazneen N, Mazid MA, Kundu JK, et al (2002). Phytochemical and Biological studies of Flacourtia indica. Dhaka Univ J Biol Sci, 11, 183-7.

Pal SK, Shukla Y (2003). Herbal medicine: current status and the future. Asian Pac J Cancer Prev, 4, 281-8.

Sehitoglu MH, Farooqi AA, Qureshi MZ, Butt G, Aras A (2014). Anthocyanins: targeting of signaling networks in cancer cells. Asian Pac J Cancer Prev, 15, 2379-81.

Shukla Y, Pal SK (2004). Complementary and alternative cancer therapies: past, present and the future scenario. Asian Pac J Cancer Prev, 5, 3-14.

Vayghan HJ, Ghadimi SS, Nourazarian AR (2014). Preventive and therapeutic roles of ginseng - focus on colon cancer. Asian Pac J Cancer Prev, 15, 585-8.

Yeh CC, Yang JI, Lee JC, et al. (2012). Anti-proliferative effect of methanolic extract of Gracilaria tenuistipitata on oral cancer cells involves apoptosis, DNA damage, and oxidative stress. BMC Complement Altern Med, 12, 142. 